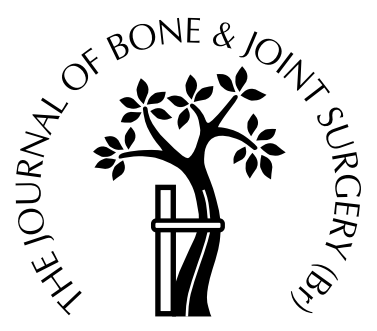

\title{
Removal of proteoglycans from the surface of defects in articular cartilage transiently enhances coverage by repair cells
}

\author{
Ernst B. Hunziker, Eva Kapfinger \\ From the M. E. Müller Institute for Biomechanics, University of Bern, Switzerland
}

$\mathbf{L}$ esions within the articular cartilage layer of synovial joints do not heal spontaneously. Some repair cells may appear, but their failure to become established may be related to problems of adhesion to proteoglycan-rich surfaces. We therefore investigated whether controlled enzymatic degradation of surface proteoglycan molecules to a depth of about $1 \mu \mathrm{m}$, using chondroitinase $\mathrm{ABC}$, would improve coverage by repair cells.

We created superficial lesions $(1.0 \times 0.2 \times 5 \mathrm{~mm})$ in the articular cartilage of mature rabbit knees and treated the surfaces with $1 \mathrm{U} / \mathrm{ml}$ of chondroitinase ABC for four minutes. The defects were studied by histomorphometry and electron microscopy at one, three and six months.

At one month, untreated lesions were covered to a mean extent of $28 \%$ by repair cells; this was enhanced to a mean of $53 \%$ after enzyme treatment. By three months, the mean coverage of both control and chondroitinase-ABC-treated defects had diminished dramatically to $0.2 \%$ and $13 \%$, respectively, but at six months both untreated and treated lesions had a similar coverage of about $30 \%$, not significantly different from that achieved in untreated knees at one month.

These findings suggest that, with time, chondrocytes near the surface of the defect may compensate for the loss of proteoglycans produced by enzyme treatment, thereby restoring the inhibitory properties of the matrix as regards cell adhesion. This supposition was confirmed by electron microscopy. Our results have an important bearing on attempts made to induce healing responses by transplanting chondrogenic cells or by applying growth factors.

J Bone Joint Surg [Br] 1998;80-B:144-50.

Received 20 December 1996; Accepted after revision 29 August 1997

E. B. Hunziker, MD, Professor and Director

E. Kapfinger, Technical Assistant

M. E. Müller Institute for Biomechanics, University of Bern, Murtenstrasse 35, PO Box 30, CH-3010 Bern, Switzerland.

Correspondence should be sent to Professor E. B. Hunziker.

(C) 1998 British Editorial Society of Bone and Joint Surgery 0301-620X/98/17531\$2.00

144
Structural defects in articular cartilage may be either confined entirely to its substance or penetrate the underlying bone. Since partial-thickness chondral lesions not only fail to undergo natural repair, ${ }^{1-4}$ but also become progressively enlarged with time, they mark the onset of diseases such as osteoarthritis. ${ }^{5,6}$ If the initially discrete lesions can be induced to heal before the situation becomes exacerbated, then these debilitating conditions may be prevented.

On the other hand, full-thickness lesions do become invaded by fibrous repair tissue albeit that this does not persist and has biomechanical properties inferior to those of articular cartilage. $^{7-10}$ This type of repair of subchondral lesions has been attributed to cells from the bone marrow and perivascular connective tissues; ${ }^{10,11}$ these cannot reach purely chondral defects.

In spite of the fact that the synovium can act as a source of repair cells under certain conditions, ${ }^{2}$ spontaneous repair never occurs. We hypothesised that potential repair cells are unable to gain a foothold in chondral lesions because of the anti-adhesive properties of the proteoglycan-rich matrix. Studies in vitro have shown that cell adhesion can be inhibited by proteoglycan molecules, ${ }^{12-14}$ particularly by those containing dermatan sulphate. ${ }^{15-17}$

We have shown recently that repair-cell adhesion is enhanced by controlled enzymatic degradation of proteoglycan molecules on the surfaces of partial-thickness defects, using chondroitinase $\mathrm{ABC} .^{2}$ Removal of the superficial proteoglycans exposes underlying collagen molecules and other proteins which are known to have cell-adhesive properties. ${ }^{18}$ The purpose of the present study was to make quantitative measurements of any increase in coverage by repair cells after such treatment and to determine whether the composition of this local population changes with time, and particularly whether these cells undergo spontaneous differentiation into chondrocytes.

\section{Materials and Methods}

Preliminary experiments. To establish the conditions required for proteoglycan removal to a depth of about $1 \mu \mathrm{m}$ from the cut surface within about four minutes, we prepared chondroitinase ABC (Sigma Chemical Company, St Louis, Missouri) at various concentrations in sodium-phosphate buffer and applied it to surface defects 
created in rabbit knees. Tissue specimens were fixed in the presence of ruthenium hexa-ammine trichloride (RHT; Johnson-Matthey and Brandenberger, Zürich, Switzerland) and embedded in epoxy resin. Ultrathin sections were prepared for electron microscopy. We assessed the extent of proteoglycan digestion by determining the loss of matrix granules. ${ }^{19,20}$ The desired effect was achieved by using chondroitinase $\mathrm{ABC}$ at a concentration of $1 \mathrm{U} / \mathrm{ml}$.

Operative procedure. We used three groups of six skeletally mature ( 8 to 10 months) New Zealand White rabbits which were killed at one (group 1), three (group 2) and six (group 3) months after surgery. The rabbits were anaesthetised by intramuscular injection of Rompun/Ketalar, and both knees exposed by parapatellar medial approaches. Superficial cartilage lesions were then created on the lateral patellar groove and the medial femoral condyle.

The instruments used to create the superficial defects were made to our specifications. (Rolf Hänggi Engineering, Grenchen, Switzerland). Each defect was $1 \mathrm{~mm}$ wide with a depth of $0.2 \mathrm{~mm}$. The length of each defect was controlled by the surgeon to be about 3 to $5 \mathrm{~mm}$.

The defects in one knee of each rabbit were left untreated as controls. On the other side, chondroitinase ABC (1 U/ $\mathrm{ml}$ ) was applied topically for four minutes, before being removed with a sterile sponge. The defects on both sides were rinsed thoroughly with physiological saline, and the knees then closed in layers.

To rule out a specific effect of chondroitinase $\mathrm{ABC}$, we treated similar defects in four additional rabbits with $2.5 \%$ trypsin (Sigma Chemical Company, St Louis, Missouri). In addition, to exclude the possibility of a systemically-transmitted effect of chondroitinase ABC from experimental-tocontrol knees, we studied another four control rabbits which had no enzyme treatment in either knee.

Tissue processing. The whole distal femur was carefully dissected free from soft tissues and fixed at ambient temperature $^{2}$ hanging free in a glass container. We used a $2 \%$ (v/v) solution of glutaraldehyde (Grogg Chemie, Bern, Switzerland) containing $0.5 \%(\mathrm{w} / \mathrm{v}) \mathrm{RHT}^{21}$ and $0.1 \mathrm{M}$ sodi- um cacodylate (Grogg Chemie, Bern, Switzerland), which was adjusted to $\mathrm{pH} 7.4$ with $\mathrm{HC} 1 / \mathrm{NaOH}$ and to 330 mosmol with $\mathrm{NaC} 1$.

After fixation for one hour, the joint surfaces were sawn into parallel slices, 1 to $2 \mathrm{~mm}$ in thickness, perpendicular to the longitudinal axis of the defect. Chemical fixation was then continued for a further three to five hours, before rinsing tissue in isotonic buffer $(0.1 \mathrm{M}$ sodium cacodylate; $\mathrm{pH}$ 7.4). Tissue slices were postfixed for three to five hours in a $1 \%(\mathrm{w} / \mathrm{v}) \mathrm{OsO}_{4}$ solution (Oxken Limited, Mulberry, UK) containing $0.1 \mathrm{M}$ sodium-cacodylate buffer ( $\mathrm{pH} 7.4$ ) and $0.5 \%$ RHT (w/v). After thorough rinsing in isotonic buffer, tissue was dehydrated in a graded series of increasing ethanol concentration, beginning at $70 \%(\mathrm{v} / \mathrm{v})$, and embedded in Epon 812.

For light microscopy and morphometric analyses, semithin sections of $1 \mu \mathrm{m}$ were cut on a Reichert OMU3 ultramicrotome and stained with Toluidine Blue O. For electron microscopy, ultrathin sections were cut on a Reichert Ultracut E ultramicrotome, and stained with uranyl acetate and lead citrate. $^{22}$

Sampling and morphometry. On average, we obtained four to five sections of each defect. The position of the initial cut made at the proximal end was random, ${ }^{23}$ but subsequent cuts were taken at fixed intervals to permit estimation of the defect reference volume by the principle of Cavalieri. $^{24,25}$ Morphometric estimations of the relative coverage of defect surfaces were made by light microscopy using $1 \mu \mathrm{m}$ sections and a cycloid test system. ${ }^{26,27}$ The sectioning direction was varied systematically relative to the vertical plane (defined as perpendicular to the joint surface). Stained sections were photographed, and morphometric estimations made on glossy prints. Statistical analyses of differences between animal groups were based on Student's $t$-test.

Proteoglycan loss attributable to enzymatic degradation was assessed qualitatively on electron micrographs by estimating changes in the numerical density of matrix granules. ${ }^{19,20}$ Similar analyses were performed on all control material.

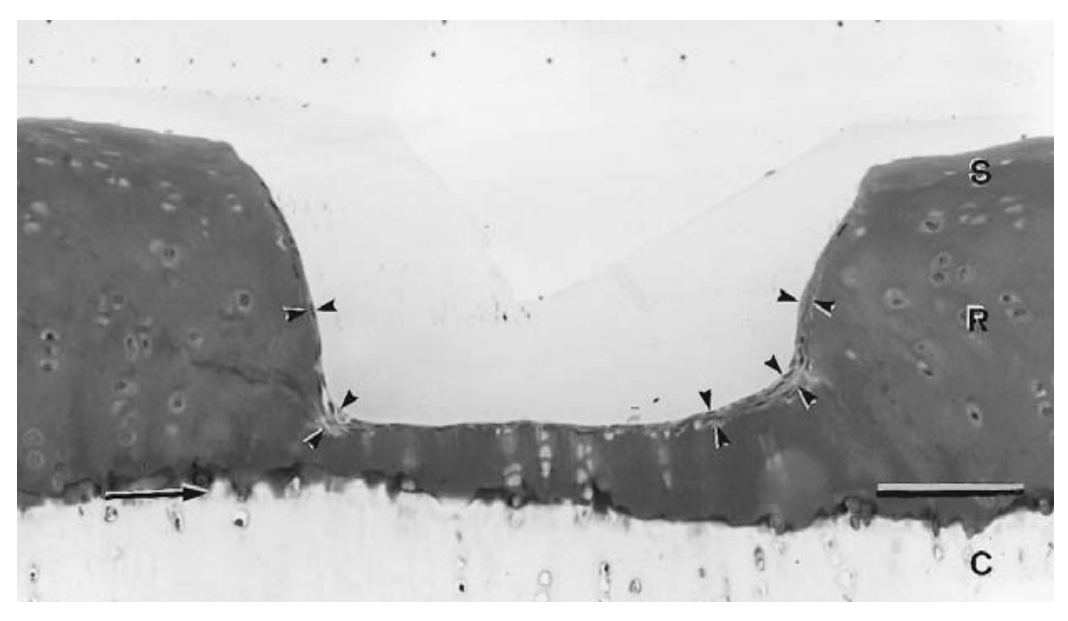

VOL. 80-B, No. 1, JANUARY 1998

\section{Fig. 1}

An articular cartilage defect at one month after local treatment with chondroitinase ABC. Most of its surface is covered by a layer of predominantly mesenchymallike cells (arrowheads), with local variations in its thickness (S, superficial zone; R, radial zone; C, calcified cartilage; arrows, tidemark; bar $=100 \mu \mathrm{m}$ ). 

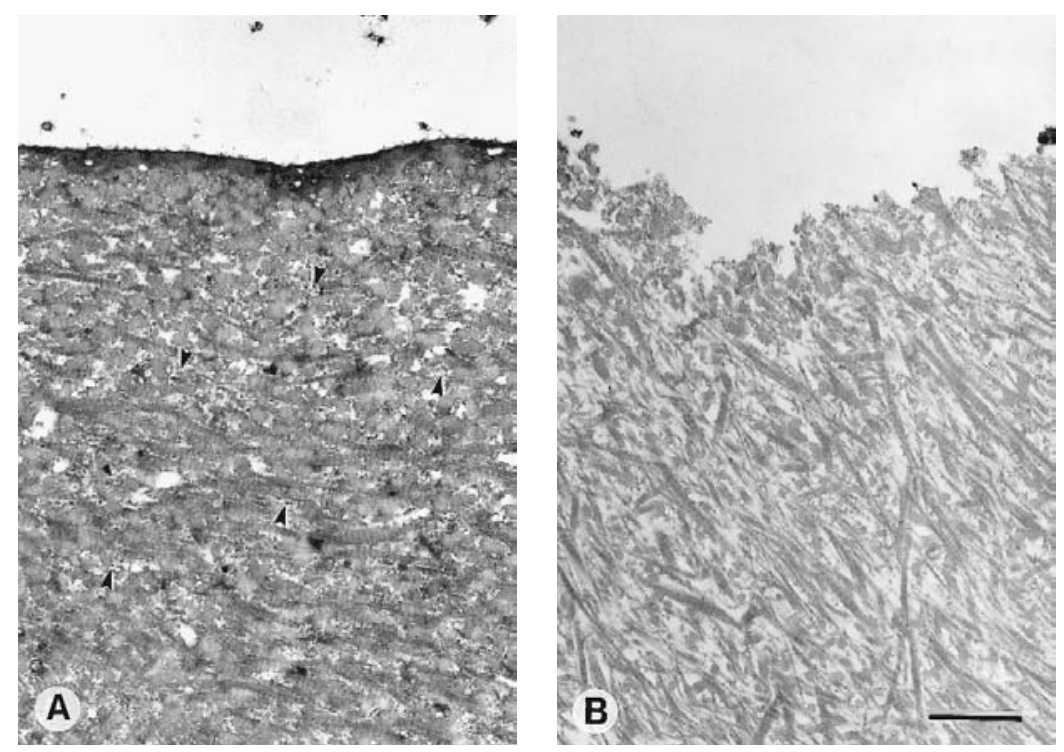

Fig. 2

Electron micrographs of the floor of defects in articular cartilage in a control knee (A) and four minutes after exposure to chondroitinase $A B C$ (B). In $A$, the interstices of the collagenous network are filled with proteoglycan-rich material, manifested as electron-dense granules (arrowheads) after precipitation with RHT. In B, the corresponding spaces are almost entirely devoid of such material, confirming the successful enzymatic digestion of proteoglycans to a depth of about $1 \mu \mathrm{m}(\mathrm{bar}=1 \mu \mathrm{m}(\mathrm{A}$ and $\mathrm{B}))$.

\section{Results}

The superficial defects were U-shaped (Fig. 1), usually penetrating the lower radial zone. The topical application of chondroitinase $\mathrm{ABC}$ at a concentration of $1 \mathrm{U} / \mathrm{ml}$ for four minutes was confirmed to degrade proteoglycan molecules to a depth of about $1 \mu \mathrm{m}$, as shown by the loss of matrix granules (Fig. 2).

Isolated groups of cells were regularly seen along the surfaces of both enzyme-treated and untreated defects. Most of these showed the elongated form characteristic of fibroblasts or undifferentiated mesenchymal connectivetissue cells (Fig. 3), but there was a smaller population of cells with a more rounded profile and abundant cytoplasm with vacuoles (phagosomes). These resembled macrophages of monocytic lineage. This adhering population of cells will be referred to collectively as 'repair cells'.

They were preferentially located either in the corners of the defects (Fig. 4), where they formed multilayered, wedge-shaped masses, or in micro-grooves produced by irregularities in the cutting process. They were also seen as single or double layers along plane surfaces, but to a less degree in untreated defects than in enzyme-treated ones. The coverage by repair cells was quantified morphometrically, and a summary of these findings is represented graphically in Figure 5. One month after surgery, the defects treated with chondroitinase $\mathrm{ABC}$ showed an approximately $25 \%$ greater coverage with repair cells than did untreated defects $(\mathrm{p}<0.05)$.

At three months after surgery, the mean cell coverage in both control $(0.2 \%)$ and enzyme-treated $(13 \%)$ defects was dramatically reduced, the difference between these two being significant $(\mathrm{p}<0.05)$. By six months, the situation had stabilised, and both control (31\%) and enzyme-treated $(33 \%)$ defects showed a similar degree of coverage. These proportions were not significantly different from those in untreated controls at one month (see Fig. 5).

The morphological characteristics of these cells did not change during the period of investigation: there were no signs of differentiation into chondrocytes. In addition to the superficial population of mesenchymal-like cells, clusters of chondrocytes were observed sporadically within the articular cartilage adjacent to the lesions; these sometimes protruded a short distance into the defect (see Fig. 4c).

The trend for increased coverage shown between the first and third months after treatment with chondroitinase $A B C$ was mirrored in trypsin-treated defects, but these were not studied at six months. The type of repair cell involved was also similar (data not presented). The control animals with untreated defects in both knees showed the same cell coverage as that documented for unilateral control lesions, thereby excluding the possibility of systemic transmission of enzyme effects (data not presented).

\section{Discussion}

It is generally recognised that partial-thickness defects in articular cartilage do not heal. The only spontaneous repair reaction is the transient proliferation of chondrocytes near the defect surfaces. ${ }^{2}$ Similar cell clusters have been reported in the early stages of osteoarthritis and have been referred to as cell-clones or brut-capsules. ${ }^{28,29}$ Their size 

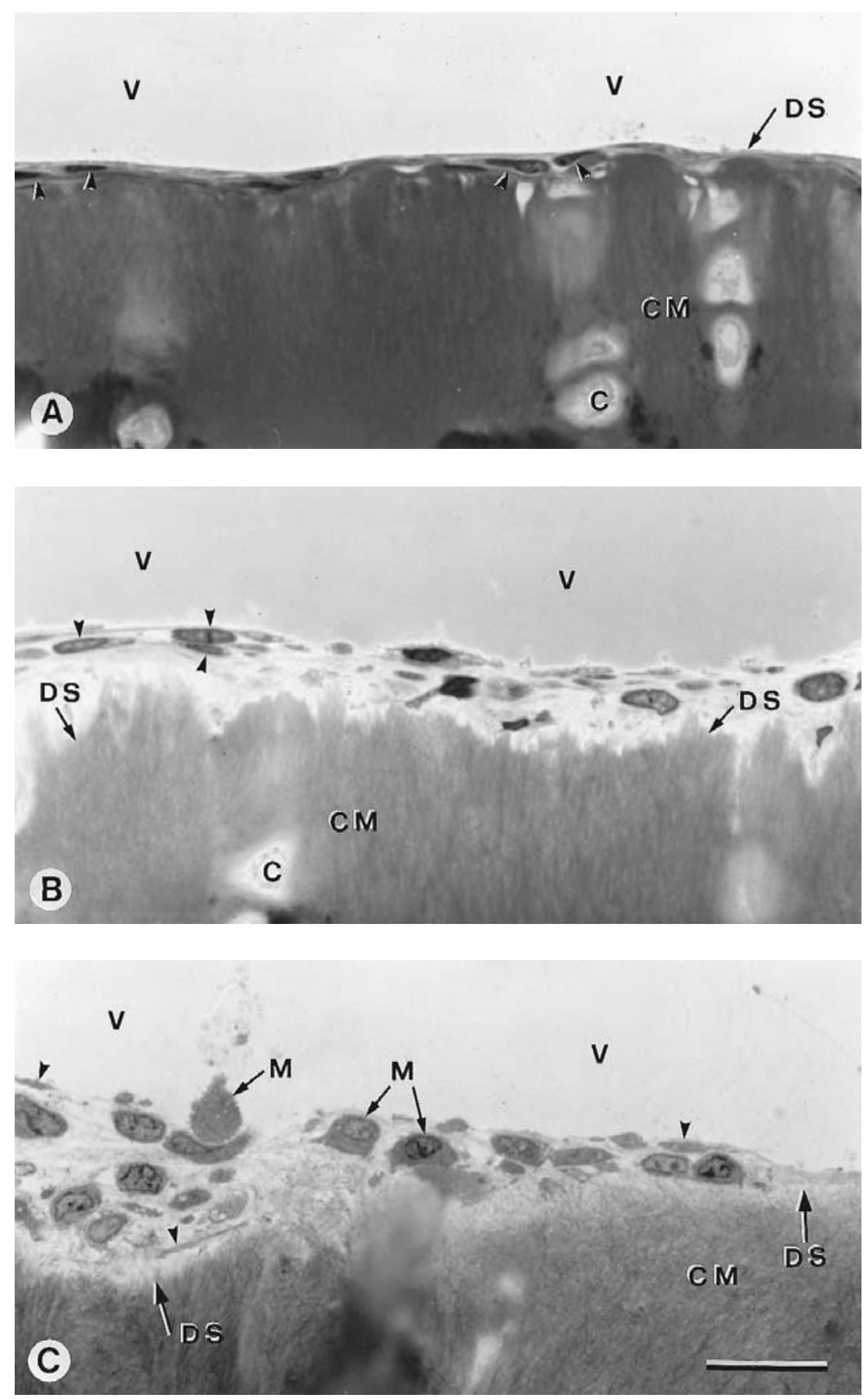

Fig. 3

Sections showing repair cells adhering to the surface of the defect at one month after treatment with chondroitinase ABC. Most of the adhering cells have a mesenchymal-like appearance (arrowheads) and build up uni- (A), bi- or occasionally trilayers (B). In some locations, however, particularly within microgrooves (C), multiple layers are also seen. Macrophages (M) are also encountered most commonly in these microgrooves (C, chondrocyte; CM, cartilage matrix; DS, defect surface; V, void of defect; bar $=20 \mu \mathrm{m}$ (A, B and C)).

remains within constrained limits, and they never proliferate significantly into the void of the lesion, although some matrix has been reported to accumulate therein. ${ }^{1}$

Our previous observations ${ }^{2}$ led us to suspect that the lack of repair of cartilage tissue stems from the anti-cell-adhesion properties of the proteoglycans within its matrix, a feature for which these molecules are renowned. We therefore studied the effect of their removal from the surface of the defect, by degrading them with chondroitinase ABC. This treatment elicited an approximately $25 \%$ increase in coverage by repair cells at one month, but this never exceeded more than a few layers and was highly variable. 

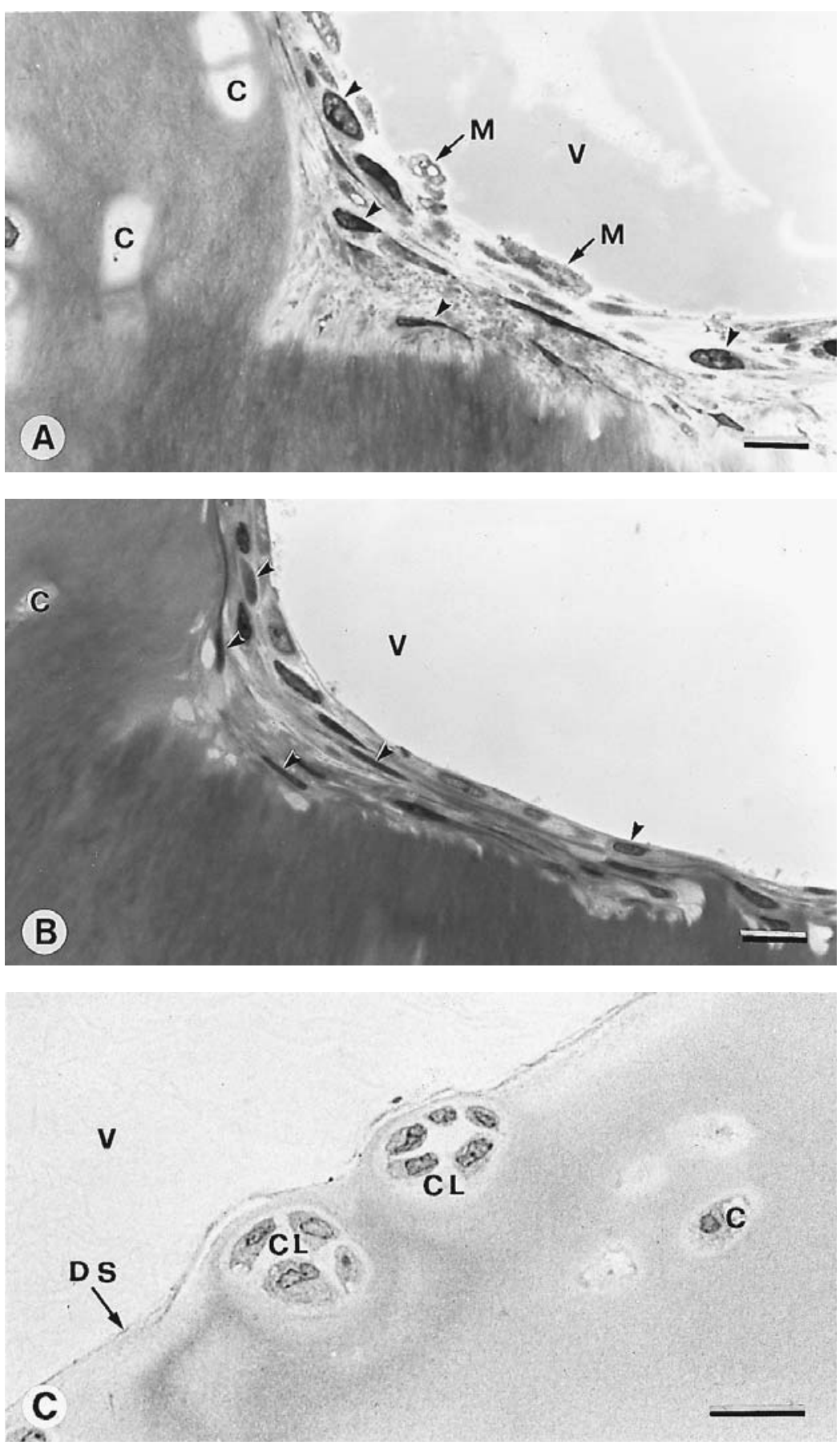

Fig. 4

Sections of the surface of defects at one month after treatment with chondroitinase ABC. In the angles (A and B), repair cells usually accumulate in multiple layers. Within the underlying articular cartilage (C), small clusters of proliferating chondrocytes are occasionally seen; these represent an abortive attempt at repair (DS, defect surface; CL, chondrocyte clusters; V, void of defect; C, chondrocyte; M, macrophages; arrowheads, mesenchymal repair cells; bar $=10 \mu \mathrm{m}(\mathrm{A}, \mathrm{B}$ and $\mathrm{C}))$.

The lesion never became filled with repair tissue.

By the third month, cell coverage had decreased considerably, in controls by about $99 \%$ and in enzyme-treated defects by about $75 \%$. At first, this finding seemed unaccountable, but more mature consideration suggested that native chondrocytes near the surface of the defect were probably stimulated anabolically by the trauma of surgery, causing an increase in proteoglycan synthesis. By six months, the situation had stabilised, with about $31 \%$ cell coverage in untreated defects and about $33 \%$ in enzyme- 


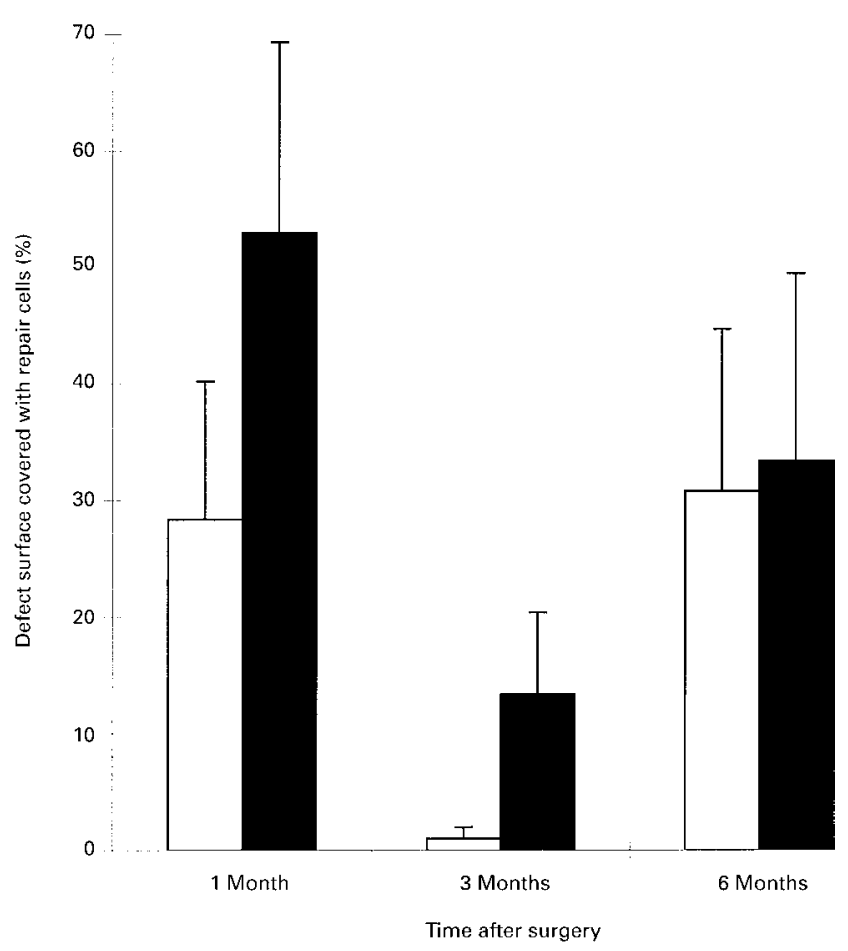

Fig. 5

Bar chart showing the mean percentage areas of defect surfaces covered with repair cells at one, three and six months after surgery in controls (white) and after treatment with chondroitinase ABC (black). The error bars show the standard errors of the means. The differences between the control and enzyme-treated percentages are significant at one $(p=0.048)$ and three months $(\mathrm{p}=0.016)$ but not at six months $(\mathrm{p}>0.05)$.

treated ones, levels which were not significantly different from those seen in control lesions at one month after surgery.

The time course of coverage, from maximal at one month to minimal at three months and 'equilibrated' at six months, is probably enzyme-specific. The effects of chondroitinase $\mathrm{ABC}$ have been described as being particularly long-acting in vitro (up to 14 days $^{30}$ ), because of nonspecific local binding to the matrix. It is therefore conceivable that non-binding enzymes would elicit a different time profile, but not necessarily a different pattern of cell coverage.

The highly variable cell coverage which we observed may point to changes in the stability of the adhesion which was established. It is not known whether repair cells, once attached, remain in position until the properties of the underlying matrix are altered by the metabolic activity of native chondrocytes in the neosynthesis of proteoglycans and the re-establishment of adhesion inhibition, or if cell adhesion follows an on-off mechanism. The investigation which we report furnishes no information on this because of its static nature. However, data from cell-adhesion studies in vitro indicate that attachment is fairly stable, provided that the composition of the underlying matrix also remains so. $^{13,14}$

The adhering cells appear to originate from the syno- vium, ${ }^{2}$ but the mechanism of migration remains to be clarified. Repair cells may well be passively transported within the cavity of the joint, but chemotactic attraction could also play a role, particularly after the enzymatic degradation; proteoglycan-degradation products are known to have a chemotactic effect on various cell types in vitro. ${ }^{31}$ Both mechanisms may be implicated; the high variance which we found suggests the influence of a number of, as yet, unknown factors.

Our finding that enzymatic removal of proteoglycans elicits only a transient increase in the local population of repair cells has important clinical implications. Attempts to induce a healing response in superficial defects of articular cartilage, for example by the local transplantation of chondrogenic cells or by the introduction of a suitable growth factor, are more likely to be effective when instigated within one month of treatment with chondroitinase $\mathrm{ABC}$.

We wish to thank N. Pattiselanno for her technical assistance, and gratefully acknowledge help from the Surgical Research Unit (Department of Clinical Research and Clinic for Large Animals) of the University of Bern. We are also indebted to C. England for constructive criticism and editing of the manuscript.

This work was supported by grants from the AO-/ASIF-Foundation, Switzerland and Orthogene Inc, California, USA.

One or more of the authors have received or will receive benefits for personal or professional use from a commercial party related directly or indirectly to the subject of this article.

\section{References}

1. Freeman MAR. Adult articular cartilage. London: Pitman Medical, 1973.

2. Hunziker EB, Rosenberg LC. Repair of partial-thickness defects in articular cartilage: cell recruitment from the synovium. J Bone Joint Surg [Am] 1996;78-A:721-33.

3. Mankin HJ. The reaction of articular cartilage to injury and osteoarthritis. N Engl J Med 1974;291:1285-92.

4. Meachim G. The effect of scarification on articular cartilage in the rabbit. J Bone Joint Surg [Br] 1963;45-B:150-61.

5. Bullough PG. Understanding osteoarthritis: the value of anatomical studies. J Rheumatol 1987;14.2:189.90.

6. Hamerman D. The biology of osteoarthritis. New Engl J Med 1989; 320:1322-30.

7. Furukawa T, Eyre DR, Koide S, Glimcher MJ. Biochemical studies on repair cartilage resurfacing experimental defects in the rabbit knee. J Bone Joint Surg [Am] 1980;62-A:79-89.

8. Kwan MK, Coutts RD, Woo SL, Field FP. Morphological and biomechanical evaluations of neocartilage from the repair of fullthickness articular cartilage defects using rib perichondrium autografts: a long-term study. J Biomech 1989;22:921-30.

9. Metsaranta M, Kujala UM, Pelliniemi L, et al. Evidence for insufficient chondrocytic differentiation during repair of full-thickness defects of articular cartilage. Matrix Biol 1996;15:39-47.

10. Shapiro F, Koide S, Glimcher MJ. Cell origin and differentiation in the repair of full-thickness defects of articular cartilage. J Bone Joint Surg [Am] 1993;75-A:532-53.

11. Meachim G, Roberts C. Repair of the joint surface from subarticular tissue in the rabbit knee. J Anat 1971;109:317-27.

12. Culp LA, Murray BA, Rollins BJ. Fibronectin and proteoglycans as determinants of cell-substratum adhesion. J Supramol Struct 1979;11: 401-27.

13. Rich AM, Pearlstein E, Weissmann G, Hoffstein ST. Cartilage proteoglycans inhibit fibronectin-mediated adhesion. Nature 1981; 293:224-6.

14. Yamagata M, Suzuki S, Akiyama SK, Yamada KM, Kimata K. Regulation of cell-substrate adhesion by proteoglycans immobilized on extracellular substrates. J Biol Chem 1989;264:8012-8. 
15. Lewandowska K, Choi HU, Rosenberg LC, Zardi L, Culp LA. Fibronectin-mediated adhesion of fibroblasts: inhibition by dermatan sulfate proteoglycan and evidence for a cryptic glycosaminoglycanbinding domain. J Cell Biol 1987;105:1443-54.

16. Rosenberg LC, Choi HU, Poole AR, Lewandowska K, Culp LA. Biological roles of dermatan sulphate proteoglycans. Ciba Found Symp 1986;124:47-68.

17. Rosenberg L, Hunziker EB. Cartilage repair in osteoarthritis: the role of dermatan sulfate proteoglycans. In: Kuettner KE, Goldberg V, eds. Osteoarthritic disorders. American Academy of Orthopaedic Surgeons, 1995:341-56.

18. McCarthy JB, Vachhani B, Iida J. Cell adhesion to collagenous matrices. Biopolymers 1996;40:371-81.

19. Hunziker EB, Schenk RK. Structural organization of proteoglycans in cartilage. In: Wright TN, Mecham RP, eds. Biology of proteoglycans. Orlando: Academic Press Inc., 1987:155-85.

20. Thyberg J. Electron microscopy of cartilage proteoglycans. Histochem J 1977;9:259-66.

21. Eggli PS, Hunziker EB, Schenk RK. Quantitation of structural features characterizing weight- and less-weight-bearing regions in articular cartilage: a stereological analysis of medial femoral condyles in young adult rabbits. Anat Rec 1988;222:217-27.

22. Hunziker EB, Herrmann W, Schenk RK. Improved cartilage fixation by ruthenium hexammine trichloride (RHT): a prerequisite for morphometry in growth cartilage. J Ultrastruct Res 1982;81:1-12.
23. Gundersen HJ, Jensen EB. The efficiency of systematic sampling in stereology and its prediction. J Microsc 1987;147:229-63.

24. Gundersen HJ, Bagger P, Bendtsen TF, et al. The new stereological tools: disector, fractionator, nucleator and point sampled intercepts and their use in pathological research and diagnosis. Apmis 1988;96: 857-81.

25. Cruz-Orive LM, Weibel ER. Recent stereological methods for cell biology: a brief survey. Am J Physiol 1990;258:148-56.

26. Baddeley AJ, Gundersen HJ, Cruz-Orive LM. Estimation of surface area from vertical sections. J Microsc 1986;142:259-76.

27. Cruz-Orive LM, Hunziker EB. Stereology for anisotropic cells: application to growth cartilage. J Microsc 1986;143:47-80.

28. Mitchell N, Lee ER, Shepard N. The clones of osteoarthritic cartilage. J Bone Joint Surg [Br] 1992;74-B:33-8.

29. Bullough PG. The pathology of osteoarthrits. In: Moskowitz RW, Howell DS, Goldberg VM, Mankin HJ, eds. Osteoarthritis: diagnosis and medical/surgical management. Philadelphia: W B Saunders Co., 1992:39-70.

30. Nahir AM, Shomrat D, Awad M. Chondroitinase ABC affects the activity of intracellular enzymes in rabbit articular cartilage chondrocytes. J Rheumatol 1995;22:702-7.

31. Moore AR, Chander CL, Hanahoe TH, et al. The chemotactic properties of cartilage glycosaminoglycans for polymorphonuclear neutrophils. Int J Tissue React 1989;11:301-7. 